\title{
TARGETED ADVERTISING IN THE BREAKFAST CEREAL INDUSTRY
}

\author{
JOSHUA BERNING* \\ Department of Agricultural and Applied Economics, University of Georgia, Athens, Georgia \\ ADAM N. RABINOWITZ \\ Department of Agricultural and Applied Economics, University of Georgia, Tifton, Georgia
}

\begin{abstract}
We examine the relationship of product characteristics of ready-to-eat breakfast cereal and targeted television advertising to specific consumer segments. We compile a unique data set that includes brand-packaging characteristics, including on-box games, nutrition information, and cobranding. We find that the relationship of television advertising and a cereal's brand-packaging characteristics varies by target audience. Our results provide insight into understanding how manufacturers strategically utilize branding, packaging, and television advertising. This can help industry and policy makers develop food product advertising policy. This analysis extends to other product markets where extensive product differentiation and promotion are present as well.
\end{abstract}

Keywords. Breakfast cereals, targeted advertising

JEL Classifications. M37, Q18

\section{Introduction}

Childhood obesity has been identified as a serious problem in the United States as about $17 \%$ of children aged 2-19 years have been defined as obese (Ogden, Carroll, and Kit, 2014). As part of the environment faced by children, food product advertising has become a relevant policy issue given its perceived role in the childhood obesity crisis. The food industry spends an estimated $\$ 1$ billion a year on marketing food and beverages to children aged 2-11 and \$1 billion a year to teens aged 12-17 (Federal Trade Commission [FTC], 2012). As such, both

This research received support from the University of Connecticut's Food Marketing Policy Center and the Zwick Center for Food and Resource Policy. We appreciate the help of Baxter Panola, Elena Castellari, Rui Huang, Hualu Zheng, and Chen Zhu on this project. We received useful comments from seminar participants at the Agricultural and Applied Economics Association Annual Meeting in Seattle, Washington, and the University of Georgia. All errors are solely the authors. This research was previously titled “Does Breakfast Cereal Advertising Target Young Children?”

*Corresponding author's e-mail: jberning@uga.edu 
industry and government have engaged in the ongoing discussion regarding the impact of television advertising on consumption of unhealthful foods (Berning, Huang, and Rabinowitz, 2014). The Institute of Medicine has recommended that industry, government, public health, and consumer groups come together to enforce standards for marketing to children (McGinnis, Gootman, and Kraak, 2006). The FTC has encouraged manufacturers to develop methods to encourage children to consume nutritious food (Aoki and Moore, 2013). Meanwhile, the Centers for Disease Control has devoted significant efforts on policy and environmental strategies to enhance healthy eating (https:/www.cdc. gov/obesity/).

Previous research has been limited and inconclusive regarding the effect of advertising on consumption of unhealthful foods and obesity outcomes. For instance, Zywicki, Holt, and Ohlhausen (2004) find that food marketing to children has not grown during the same time that obesity has increased. Desrochers and Holt (2007) find that children were not exposed to more food advertisements and did not see more advertising for low-nutrition foods when comparing 1977 with 2004, a time span with significant increases in childhood obesity. Andreyeva, Kelly, and Harris (2011) find an association between fastfood advertising and body mass index for overweight and obese children, but no association between food advertising and average body weight. Dhar and Baylis (2011) examine the effect of a ban on television advertising to children in Quebec on fast-food consumption. They find that the ban decreased the probability of going to a fast-food restaurant, although there was no difference in expenditures if the decision was made to go to the restaurant. Overall, it is unclear if or how food advertising affects unhealthful consumption or obesity outcomes with children. ${ }^{1}$

The purpose of this research is to provide a more detailed examination of advertising to help inform future research investigating the effects of advertising on unhealthful food consumption and obesity outcomes. We investigate how food manufacturers employ targeted advertising to promote various food products while also identifying factors that are associated with target advertising to specific audiences. Specifically, we focus on ready-to-eat (RTE) breakfast cereals and the healthiness of products advertised to children, teens, and adults. Altogether, this highlights how the entire product marketing mix is developed to targeted specific audiences.

Targeted advertising allows firms to reach specific market segments using media specifically designed to be of interest to these consumers. By showing a

1 Although several other studies suggest a link between advertising and obesity, Beales and Kulick (2013) suggest that obesity results from sedentary activity (i.e., the total number of hours watching television) rather than television advertisements. An important distinction must be made between correlation and causation. 
particular advertisement to the most receptive audience, advertising effectiveness is improved and advertising waste is reduced (Anand and Shachar, 2009; Chandra and Kaiser, 2014). Targeted advertising also suggests a more complex promotional strategy than just making a discrete decision to advertise or not. It suggests that product characteristics correspond to promotional activities targeted to specific audiences. That is, products with certain brand-packaging characteristics are more likely to have advertising targeted at specific market segments. By examining the relationship between product characteristics and targeted advertising, we obtain a richer understanding of firm marketing strategies.

In this study, we focus on targeted advertising of television media for the RTE breakfast cereal industry. We consider how product characteristics (nutritional quality, packaging, and cobranding) prompt product television advertising to specific consumer segments (children, teenagers, and adults). Television advertising is measured using gross rating points (GRPs), which are determined by the number of people in a specific segment that see an advertisement multiplied by the number of times they see it. We compile a unique data set that includes detailed information regarding brand-packaging characteristics, including onbox games, nutrition information, and other forms of cobranding. Such detail allows us to distinguish how firms alter television advertising on the basis of package-based promotional strategies.

Employing these data sets, we estimate the relationship of product characteristics and advertising GRPs while controlling for sample selection of firms that choose when to advertise. Controlling for sample selection allows us to explicitly deal with intermittent advertising behavior generally referred to as pulse advertising (Feinberg, 1992; Simon, 1982). As such, we are able to separate out the extensive and intensive advertising margin, the latter identifying the intensity of firms that choose to advertise their cereal to children. Our results reveal that a cereal's nutritional profile, package attributes, and cobranding correspond to television advertising targeted to specific audiences.

The results of this analysis contribute to our understanding of how breakfast cereal manufacturers strategically utilize branding, packaging, and television advertising. Rather than advertising being uniformly applied to all market segments, firms in the industry target specific segments based on the characteristics of the product being advertised. This reveals a more nuanced description of advertising behavior that has not been discussed in previous studies.

Importantly, our findings contribute to understanding how products with different quality characteristics are advertised to different market segments. This can ultimately help industry and policy makers to develop appropriate measures for guiding food product advertising in the future. The implications of this analysis extend to other product markets where extensive product differentiation and promotion are present as well. 


\section{Motivation}

Advertising a brand-name product on television, particularly national television, can be an expensive marketing strategy. To help maximize advertising benefits, firms may choose to engage in targeted advertising. Thus, targeted advertising can be an integral part of a firm's marketing strategy in industries where firms compete with differentiated products. Iyer, Soberman, and Villas-Boas (2005) show that targeted advertising can be even more valuable than target pricing in a competitive environment. Johnson (2013) shows that improved targeting of advertising can raise the profits of firms. In a large-scale field experiment, Goldfarb and Tucker (2011a) show that targeting online advertising to specific website content increased consumer purchase intent. In a separate study, Goldfarb and Tucker (2011b) examine privacy regulations that restrict advertisers from collecting user data in order to target their advertisements. They find that such restrictions made online advertising far less effective at changing stated purchase intent. Other research on targeted advertising focuses on the price of advertising in the newspaper industry (Chandra, 2009) and the television industry (Goettler, 2012).

The breakfast cereal industry is ideal for examining targeted advertising for several reasons. First, breakfast cereal is a heavily consumed product in the United States, and competing firms in the industry rely on vast amounts of product differentiation. The product category includes several consumer segments (children, adults, etc.) and offers a wide variety of flavor profiles (chocolate, fruity, etc.) and nutritional content (high fiber, high sugar, etc.) within each segment. Consistent with such large-scale product differentiation, the breakfast cereal industry also employs a significant amount of television advertising. In fact, cereal companies spent \$264 million on advertising in 2011 (http://cerealfacts.org). Advertising in the cereal industry has been documented to have an advertising-to-sales ratio four to six times higher than other food industries (Nevo, 2001). Cereal has also been consistently the second most advertised product (following fast-food restaurants) to children aged 2-11 from 2004 to 2015 (Frazier and Harris, 2016).

With regard to breakfast cereals, manufacturers recognize that sugar appeals to children. In fact, General Mills refers to a "sweetness threshold" of roughly 9 grams of sugar per serving, which is "the breaking point where the sugar level is so low that the sweetness is not enough for a kid to eat it on day two after trying it on day one" (Jargon, 2011, p. B1). Given the demand for sugary cereals, we might expect that sugar content would be a primary driver of what products are advertised, particularly to children. With regard to adults, however, sugar may not be an advantageous characteristic, as adults face a completely different choice set for managing their health. To this point, Schwartz et al. (2010) found that as the nutritional profile of a cereal became worse, the cereal was more heavily advertised to children. A heart-healthy breakfast cereal advertisement may fall 
on deaf ears if targeted to children, just as a Cocoa-covered, high-sugar cereal advertisement may not appeal to adults. In fact, Berning, Huang, and Rabinowitz (2014) find that the average nutritional content of advertised children's cereals is one with more fat and sugar and less protein.

In addition to nutritional quality differentiation, breakfast cereals utilize their brand packaging to an extent that few other products do. Breakfast cereal packaging is often covered in brand characters, promotional opportunities, nutritional claims, and other engaging marketing strategies. Product brand images such as Toucan Sam, the Trix rabbit, and Cap'n Crunch are identifiable characters that entice young consumers. Consequently, products that have certain brand profiles may be ideal products to advertise to specific target audiences. This is an issue that is not just isolated to food products as it has been documented that tobacco advertisers had been known to use characters to appeal to young audiences (Kelly et al., 2000). This practice subsequently ended with tobacco manufacturers being subject to legal agreements and government policies prohibiting such marketing practices.

Brand profiles are also enhanced by product packaging that often includes other attractions. This includes things like games on the box, toys in the box, and other forms of brand enhancements. In particular, children's cereals often make use of what are called advergames, which integrate brand characters or identify with online video games (Lee et al., 2009). In a study of 7- and 8-year-olds, Mallinckrodt and Mizerski (2007) found that although the children understood the persuasive intent of a Froot Loops advergame, the children who played the game still showed greater preference for Froot Loops over other cereals.

Further, breakfast cereal packaging is used to promote product cobranding. This is a brand alliance strategy between two or more products being simultaneously offered to consumers (Geylani, Inman, and Ter Hofstede, 2008). The expectation is that cobranding can help gain increased access to new markets and can signal reputation and quality (Rao, Qu, and Ruekert, 1999; Rao and Ruekert, 1994). Examples of cobranding include cereal boxes with television or movie themes, athlete endorsements, or cartoon endorsements. If a cereal company is attempting to attract consumers by cobranding its product, such cobranding efforts might affect the decision to advertise and who to target with such advertisements.

The focus of this research is to examine the relationship of observable product characteristics, including cereal packaging and cobranding, and the promotion of the product via television advertising. Although Schwartz et al. (2010) previously examined the nutritional quality of cereal advertised to children, they relied on a nutrition score, which aggregates various nutrients. Our analysis allows us to examine the influence of specific nutrients, in particular, sugar. In addition, Schwartz et al do not account for other types of product characteristics, such as packaging and cobranding. In their analysis of advertising, Berning, Huang, and Rabinowitz (2014) disaggregate the nutritional content of cereals, but they also 


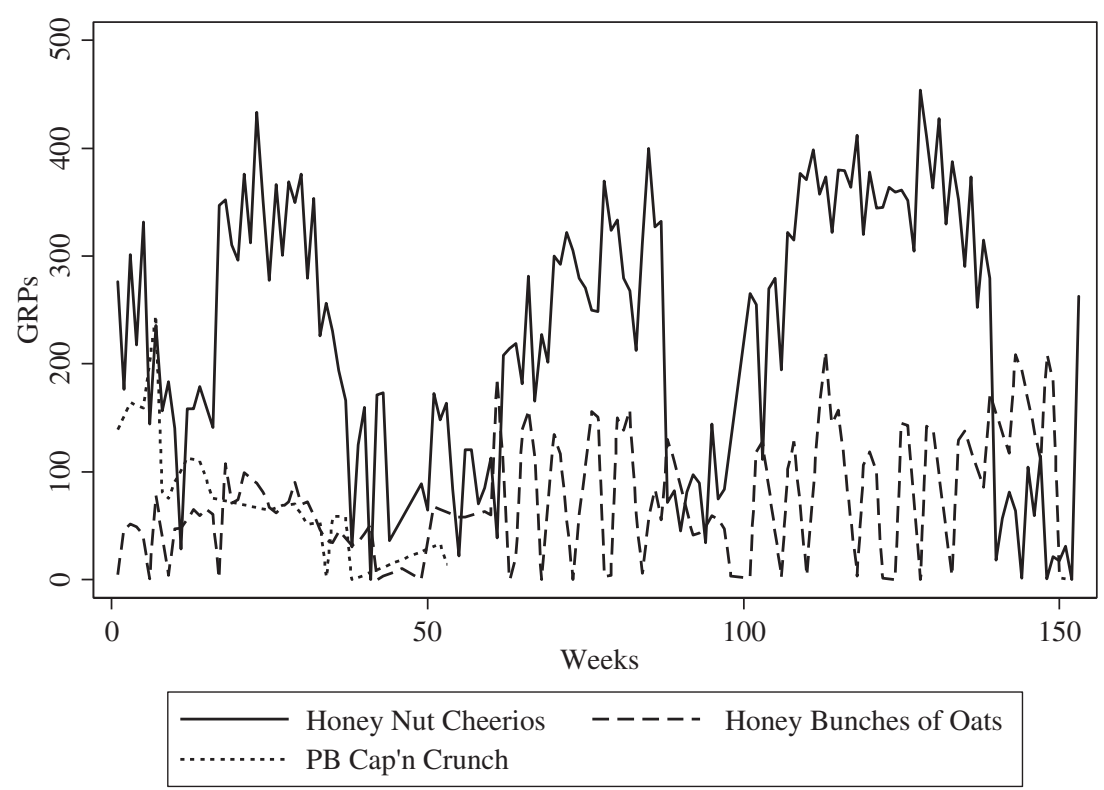

Figure 1. Children's Advertising Gross Rating Points (GRPs) for Three Breakfast Cereals

do not consider other product characteristics. Finally, neither of the previous analyses accounts for intermittent pulse advertising, where firms strategically advertise in pulses rather than continuously. We discuss this in further detail in the following sections.

\section{Data}

We compile a unique data set to estimate our empirical model. For the cereal advertising data, we use Nielsen Media Research weekly national advertising data from 2006 to 2008 for 113 different breakfast cereals. These data include, by brand, advertising expenditures and GRPs broken down into three groups: ages 2-11 (children), ages 12-17 (teens), and ages 18 and up (adults). GRPs are a measure of the reach (percentage of the targeted segment seeing the advertisement) times the frequency (number of times viewed) of a television commercial as calculated by Nielsen based on measured viewing of participating Nielsen U.S. TV families. For example, if $40 \%$ of the target audience views an advertisement five times in a week, the GRPs for that segment are 200. Alternatively, if $100 \%$ see the advertisement twice, GRPs are 200 .

Looking at the advertising GRPs, there are relevant differences in the advertising strategy for different products. Figure 1 provides an example of advertising GRPs to the children's group for three popular cereal brands. Honey Nut Cheerios illustrates a cereal that is pulse advertised continually during our 
data period. There are frequent spikes in advertising GRPs and occasional zeros in advertising. Honey Bunches of Oats shows a similar pattern of advertising over the entire data set, but with a greater frequency of zeros. This provides an important contrast regarding how two cereals can be advertised at different levels of intensity. Further, the zero advertising that we observe reflects a pause in advertising rather than a complete stop in advertising during our data period. Finally, Cap'n Crunch demonstrates pulse advertising as well, but only for 1 year before it is no longer advertised.

We cannot distinguish between advertising that completely stops and advertising that stops during our data period and then resumes after our data period. For instance, certain cereals could have a break between periods when they are advertised, but we do not observe the continuance of advertising after the break. This should not affect our analysis, but limits the external validity of our results to the cereals we are examining during our time frame. However, this is relatively extensive and inclusive of national advertising in the United States.

We use the Nielsen data to identify breakfast cereals that are advertised from 2006 to 2008. Then, we use several other data sets to identify the characteristics of the products being advertised during that time. The first data set is the Mintel Global New Products Database (http://www.mintel. com/global-new-products-database). Mintel provides photographs of most new grocery store products in U.S. markets since 1985. This includes any changes to product packaging as well. This allows us to identify if a product has a brand character, a nutritional claim, or even some form of cobranding during our data set. It also allows us to capture nutrition information for a large share of products over time.

Although Mintel has product packaging information for all the cereals advertised in our data, nutrition information is sometimes lacking. For products for which Mintel does not have nutrition information, we rely on the U.S. Department of Agriculture, Agricultural Research Service National Nutrient Database (2006-2008) (https://ndb.nal.usda.gov/ndb/). This allows us to gather fairly accurate nutrition data. ${ }^{2}$ We also rely on the Canadian Nutrient File database provided by Health Canada (2010) (http://www.hc-sc.gc.ca/fn-an/ nutrition/fiche-nutri-data/index-eng.php) and manufacturer's websites for the few remaining cereals that are not included in the other databases. Although the accumulated data may not reflect changes in the nutritional quality of breakfast cereals to the exact day, we do not perceive this as a major problem. Breakfast cereals do not have large changes in their ingredients. That is, a children's cereal with high sugar content does not suddenly become an adult cereal with high

2 Based on personal communication (on June 1, 2013) with the U.S. Department of Agriculture, Agricultural Research Service, the Nutrient Database is updated as frequently as possible but may not have the most current nutrition information available. 
Table 1. Nutrition Profile of Breakfast Cereals in Data Set

\begin{tabular}{|c|c|c|c|c|}
\hline Per gram & Mean & Standard Deviation & Minimum & Maximum \\
\hline Calories & 3.83 & 0.29 & 1.92 & 4.44 \\
\hline Total fat $(\mathrm{g})$ & 0.05 & 0.03 & 0.00 & 0.13 \\
\hline Sodium (mg) & 5.08 & 1.87 & 0.00 & 9.67 \\
\hline Fiber $(\mathrm{g})$ & 0.06 & 0.05 & 0.00 & 0.27 \\
\hline Sugar $(\mathrm{g})$ & 0.31 & 0.10 & 0.08 & 0.50 \\
\hline Protein (g) & 0.07 & 0.03 & 0.02 & 0.17 \\
\hline Serving size $(\mathrm{g})$ & 35.50 & 10.06 & 25.00 & 100.00 \\
\hline
\end{tabular}

Table 2. Breakfast Cereal Promotion Data Summary Statistics

\begin{tabular}{lrrrr}
\hline \hline Variable & Mean & Standard Deviation & Minimum & Maximum \\
\hline Children GRPs & 74.27 & 109.56 & 0 & 821.88 \\
Teen GRPs & 21.44 & 27.74 & 0 & 180.08 \\
Adult GRPs & 36.56 & 61.87 & 0 & 415.81 \\
Cereal age & 26.59 & 24.13 & 0 & 109.00 \\
Firm price (thousands of dollars) & 1.93 & 2.87 & 0.05 & 153.20 \\
Market unit price (thousands of dollars) & 2.60 & 0.75 & 1.22 & 4.89 \\
Nutrition claim & $46.5 \%$ & - & - & - \\
Game on box & $29.4 \%$ & - & - & - \\
Toy in box & $27.8 \%$ & - & - & - \\
Purchase deal & $2.6 \%$ & - & - & - \\
Online game & $7.8 \%$ & - & - & - \\
Brand character & $38.0 \%$ & - & - & - \\
Movie character & $18.1 \%$ & - & - & - \\
Cartoon character & $8.6 \%$ & - & - & - \\
TV character & $3.2 \%$ & - & - \\
Sports character & $4.4 \%$ & - & - \\
\hline \hline
\end{tabular}

Note: GRP, gross rating point.

fiber. As such, the nutritional data we compiled represents the most accurate data available.

Our final data set includes the product, packaging, and nutritional profile of cereals advertised on television from 2006 to 2008. As cereals vary in both package and serving size, we normalize the nutritional data by grams. As shown in Table 1 , there is a wide variance in the nutritional content of the breakfast cereals in our data set. The average serving size is about 35 grams, or just over 1 ounce.

Looking at the promotional data (Table 2), we can see that breakfast cereals are more heavily advertised to children than adults and teens. In addition, there is a tremendous range in advertising GRPs to all groups, especially children. A large number of cereals $(46.5 \%)$ have nutritional claims on their box. Other common types of product promotion include a game on the box $(29.4 \%)$, a toy in the 
Table 3. Nutrition Profile of GRP-Weighted Average Cereal versus Selected Cereal Products

\begin{tabular}{lcrrr}
\hline \hline & Cereals Advertised to Children & Cheerios & Corn Flakes & Frosted Flakes \\
\hline Calories & 119 & 100 & 100 & 110 \\
Fat (g) & 1.61 & 2 & 0 & 0 \\
Saturated fat (g) & 0.24 & 0 & 0 & 0 \\
Sodium (mg) & 173.5 & 160 & 200 & 140 \\
Fiber (g) & 1.20 & 3 & 1 & 1 \\
Sugar (g) & 11.15 & 1 & 3 & 1 \\
Protein (g) & 1.54 & 3 & 2 & 1 \\
\hline \hline
\end{tabular}

box $(27.8 \%)$, and the use of a brand character $(38 \%)$. Television advertising of cobranded cereals is relatively common for brand movie characters $(18.1 \%)$ and cartoon characters $(8.6 \%)$, but less so for TV characters $(3.2 \%)$ and sports characters $(4.4 \%)$.

To provide a sense of the type of cereal products that are advertised, we calculate the nutritional profile of the GRP-weighted average cereal and compare it with three other popular cereals (Table 3). Specifically, we use children's GRPs to create our hypothetical cereal product. Although most of the nutritional content is fairly similar, the weighted average sugar content of advertised cereals is higher than Cheerios and Corn Flakes and similar to Frosted Flakes. Cheerios also has higher fiber and protein than the average cereal advertised to children in our data set. ${ }^{3}$

\section{Empirical Approach}

In our analysis, we treat product advertising as a function of the brand characteristics. Specifically, we specify firm $i$ 's advertising of brand $j$ at week $t$ as

$$
A d v_{i j t}^{g}=f^{g}\left(X_{j t}, \text { firm price }_{j t}, m k t \operatorname{comp} p_{-i t}^{g}, \theta_{i}, \theta_{t}, \boldsymbol{\beta}, \varepsilon_{i j t}\right),
$$

where $A d v$ is the number of advertising GRPs for three age groups $(g)$ : children, teens, or adults. Disaggregating by these age groups allows us to identify how firms advertise their products to specific market segments. The matrix $X$ includes product nutritional characteristics, box characteristics, product age, and different forms of product cobranding. Box characteristics include whether there is a game on the box, an online game advertisement, a product coupon, a toy in the box, or a nutritional claim on the box and whether there is a brand character appearing on the box (e.g., Toucan Sam). Cobranding includes whether the box includes the image of a movie, cartoon, or television character or a celebrity/athlete. Firm

3 Note, we do not consider other micronutrients in these cereals that may also be important for children. 
price is the price paid for advertising calculated as the total expenditures for all breakfast cereal advertising divided by the total number of GRPs for all age groups for brand $j$ at time $t$. The aggregate GRPs purchased by all other firms at time $t$ for age group $g$ are denoted by $m k t$ comp. This is included to capture the competitive effects of other firm advertising. $\boldsymbol{\beta}$ is a vector of parameter estimates, $\varepsilon$ is an independent and identically distributed error term, and $f$ is a functional form that we assume to be linear and different for each age group.

In equation (1), we consider the product brand, including its characters and images, as given for any week in our data set. That is, we assume that prior to selecting advertising for the product, the firm has already determined its characteristics. Conceptually, this could be thought of as a hedonic advertising function where the "market-determined" product characteristics dictate the extent of advertising.

We recognize, however, that for certain cereal products, both firm price and cobranding variables may be endogenous to the advertising decision. First, there may be unobserved market characteristics that affect both advertising and the cobranding or pricing decisions. Failing to control for these would result in bias. Alternatively, a firm could potentially change its cobranding of a particular cereal after having made the decision to advertise the cereal or at the same time. Such reverse causality or simultaneity would also bias estimates of the relationship of product characteristics and television advertising.

To explicitly mitigate potential endogeneity because of omitted variables, we include firm fixed effects $\left(\theta_{i}\right)$ to account for time invariant unobservables that might bias estimates of cobranding. To account for temporal factors that could lead to endogeneity, we include seasonal dummy variables, dummy variables for each quarter, and a week time trend $\left(\theta_{t}\right)$. However, there could still be time-variant unobservable factors that bias our estimates to some degree. To examine this, we also estimate models where we include quarter dummy variables interacted with each firm effect.

By using weekly observations, we avoid simultaneity that might occur because of aggregation over longer time periods such as a month. There could still be simultaneity bias, however, even if reverse causality is not present. To account for this, we also estimate equation (1) with lagged values for box characteristics and product cobranding. This provides a stronger case that these other marketing characteristics were determined prior to the television advertising decision. ${ }^{4} \mathrm{We}$ do not include lagged nutritional values because they do not vary across the majority of cereals in our sample. In our analysis, we evaluate a 1 week and 1 month lag.

Nelson (2008) and Nelson and Young (2008) use a similar approach to examine whether alcoholic beverage companies target youths with magazine advertisements. Specifically, they model beverage company demand for magazine

4 We appreciate this suggestion from an anonymous reviewer. 
advertising in terms of magazine readership characteristics. Overall, they find no evidence of targeting teens with advertising for alcoholic beverages. One concern with Nelson and Young's approach that we try to address is that they do not control for intermittent advertising, which is prominent in television advertising. That is, firms often engage in pulse television advertising, which is defined by intermittent advertising rather than a constant stream of advertising. The use of pulse advertising derives from the expectation that consumer response to advertising is a sigmoidal function with marginally decreasing returns to advertising (Feinberg, 1992; Simon, 1982). From an empirical standpoint, there are two different data-generating processes to consider with pulse advertising: the decision to advertise and how much to advertise. ${ }^{5}$ Failing to control for the first process will bias estimates of the second. As a result, empirical results will tend to underpredict zero advertising and overpredict positive advertising values.

To this point, we explicitly define the decision of the firm to advertise as

$$
y_{i j t}=g\left(X_{j t}, \text { market price }-i t, \theta_{i}, \theta_{t}, \delta, \xi_{i j t}\right),
$$

where $y$ is a discrete variable that equals 1 if the firm advertises and 0 otherwise. We also include firm and time fixed effects and an error term $\xi_{i j t}$ that is assumed to be correlated with the error term in equation (1)

In equation (2), we include the market price for a single unit of advertising, market price, which is calculated as the average price paid for a single unit of advertising by all other firms in the market, generally a 30-second spot. We exclude this variable in equation (1) and instead include the firm's own GRP price, which is the actual price a particular firm pays per GRP of advertising. By excluding the market unit price in equation (1), we assume that the market price for a unit of advertising affects the decision to advertise, but not the specific amount of advertising purchased by a firm. That is, if a firm observes high unit prices paid by other firms for advertising, it may choose to stay out of the advertising market. Similarly, low unit prices may encourage firms to advertise. If a firm decides to advertise, then it pays its own negotiated GRP price.

A relevant question is whether this exclusion restriction is appropriate. In particular, the market unit price may be similar to the GRP price for each firm. Looking at the summary statistics for each variable (Table 2), we can see that market price has an average price of $\$ 2,600$ per unit and firm price has an average price of $\$ 1,930$ per GRP. However, firm price exhibits far more variation with nearly four times the standard deviation and a much larger range. The correlation between the two variables is 0.085 , suggesting that they are not highly related.

5 A firm may also strategically select the length of time between advertising pulses. Our approach only accounts for the discrete decision of firms to advertise or not in the current period, without considering time between pulses. We leave that for future research. 
Finally, we estimate equation (1) using ordinary least squares and include market price as an explanatory variable. The variable is not statistically significant for children, teen, or adult GRPs (results available on request). This suggests that the market price does not predict how many GRPs a firm purchases. We discuss how well market price predicts the decision to advertise in the Section 5.

There are several ways to estimate equations (1) and (2). If the error terms in each equation are uncorrelated, then we can ignore equation (2) and just estimate equation (1). Nelson (2008) and Nelson and Young (2008) estimate an equivalent specification to equation (1) using both Poisson and negative binomial models, thereby ignoring the initial decision to advertise or not. If the error terms are correlated, however, failing to account for the first-stage decision to advertise will bias estimates of how much to advertise in the second stage. Consequently, we explicitly account for both processes.

\section{Results}

We estimate equations (1) and (2) using negative binomial and Poisson models for children, teen, and adult GRPs and cluster the standard errors by brand, which should help account for autocorrelation and heteroskedasticity in our analysis. We initially examine whether the zero-inflated negative binomial or Poisson models are more appropriate based on their reported Akaike information criterion (AIC), Bayesian information criterion (BIC), and a plot of their predicted values. Both the negative binomial and Poisson models, without the first-stage model, underpredict zero advertising for a given brand. Further, the negative binomial model then overpredicts low levels of positive advertising. This demonstrates the importance of separately modeling the decision to advertise or not in the first stage.

Although estimating the first-stage model improves the overall predictive power of the model, none of the key variables in this step are statistically significant (Table 4). We then compare the zero-inflated models, which estimate the first-stage decision to advertise, and we find that the zero-inflated negative binomial performs better than the zero-inflated Poisson based on AIC and BIC criteria (not reported). We report results for the zero-inflated negative binomial estimates.

In the second-stage estimates of cereal advertising (Table 5), sugar has a significant, positive association with advertising to children, as would be expected based on the data in Table 3. This result disappears with teenage audiences, however. Further, sugar appears to have a negative association with adult cereals. Although Schwartz et al. (2010) found that cereals with worse nutritional profiles were advertised more to children, these results highlight that the decisive nutrient is sugar. Further, our results highlight how advertising to children varies from advertising to teenagers with respect to sugarsweetened beverages. Interestingly, the fat content also appears to have a positive 
Table 4. First-Stage Estimates of Firm Decision to Advertise

\begin{tabular}{llcc}
\hline \hline Variables & Children GRPs & Teen GRPs & Adult GRPs \\
\hline Market competition & 0.000795 & -0.0779 & -0.0196 \\
Calories & -0.276 & -0.338 & -0.381 \\
Total fat & -9.455 & -9.168 & -8.893 \\
Sodium & -0.0278 & -0.0294 & -0.03 \\
Fiber & -1.919 & -2.084 & -2.529 \\
Sugar & 1.128 & 1.138 & 0.954 \\
Protein & 7.161 & 7.198 & $7.719^{*}$ \\
Organic & $0.865^{* * *}$ & $0.863^{* * *}$ & $0.867^{* * *}$ \\
Product age & -0.00342 & -0.00333 & -0.00317 \\
Market price & -0.0553 & -0.0425 & -0.0713 \\
Observations & 5,824 & 5,824 & 5,824 \\
\hline \hline
\end{tabular}

Notes: ${ }^{* * *} P<0.01,{ }^{* *} P<0.05,{ }^{*} P<0.1$. Standard errors clustered by brand. GRP, gross rating point.

Table 5. Zero-Inflated Negative Binomial Estimates of Advertising GRPs

\begin{tabular}{lccc}
\hline \hline & & & \\
& & Advertising GRPs & \\
\cline { 2 - 4 } Variables & Children GRPs & Teen GRPs & Adult GRPs \\
\hline Market competition & 0.021 & $0.286^{* * *}$ & $-0.146^{* * *}$ \\
Calories & $-0.543^{*}$ & -0.0702 & -0.0759 \\
Total fat & $4.265^{*}$ & 1.318 & 0.198 \\
Sodium & 0.00413 & -0.0267 & $-0.0799^{* * *}$ \\
Fiber & -1.712 & -1.911 & $-3.689^{* *}$ \\
Sugar & $3.058^{* * *}$ & -0.0296 & $-4.382^{* * *}$ \\
Protein & -1.723 & -1.648 & 1.626 \\
Organic & 0.1 & 0.191 & 0.155 \\
Product age & $-0.00841^{* * *}$ & $-0.00765^{* * *}$ & $-0.00738^{* * *}$ \\
Firm price & $-0.297^{* * *}$ & $-0.161^{* * *}$ & $-0.0326^{*}$ \\
Nutrition claim & 0.0404 & -0.00617 & $-0.254^{* *}$ \\
Game on box & 0.0728 & 0.0514 & 0.124 \\
Toy in box & -0.2 & -0.118 & -0.0588 \\
Purchase deal & 0.0976 & -0.0592 & 0.0442 \\
Game online & 0.259 & 0.137 & 0.0624 \\
Brand character & $0.395^{* * *}$ & $0.197^{*}$ & 0.196 \\
Movie character & $0.262^{*}$ & 0.117 & -0.024 \\
Cartoon character & -0.27 & $-0.370^{* *}$ & $-0.540^{* * *}$ \\
TV character & $-0.285^{*}$ & $-0.289^{*}$ & $-0.370^{* *}$ \\
Sports character & -0.355 & -0.023 & $0.568^{* *}$ \\
Observations & 5,824 & 524 & 524 \\
\hline \hline
\end{tabular}

Notes: ${ }^{* * *} P<0.01,{ }^{* *} P<0.05,{ }^{*} P<0.1$. Standard errors clustered by brand. GRP, gross rating point.

relationship with advertising to children. Again, fat is often an indicator of more palatable taste, suggesting the benefit of advertising "tasty" cereals. Most notable about these findings on sugar and fat is that even after controlling for other types of cobranding and packaging, sugar and fat have a positive relationship 
with advertising to children. To the extent that policy makers seek to regulate advertising of unhealthful products to children, these results emphasize the importance of regulating advertising to young children.

It is not surprising that sugar and sodium content lead to reduced advertising to adults who tend to be more conscientious about their diets than young children. At the same time, fiber content and nutritional claims on the front of the package also lead to reduced advertising to adults. This is a bit surprising because of the health benefits of fiber; however, it may be that high fiber cereals or cereals with higher nutritional quality are associated with less appealing taste. For instance, Berning, Chouinard, and McCluskey (2011) found that when retailers displayed nutrition labels for more healthful microwave popcorn, sales for that popcorn declined. In this case, advertising high-fiber products, even if adults should eat them, may not appeal to a wide enough television audience to be an effective advertising strategy. This is purely speculation, however, and would need to be further studied to confirm this assertion.

Having a brand character on the box leads to a significant increase in GRPs to children and teens. This suggests that firms seek to promote cereals with a well-developed brand image involving a brand character. If children seek out identifiable brand characters while shopping, they first need to identify with the brand character. Thus, initial television advertising efforts can help promote the brand character.

With regard to cobranding, we find interesting results across all age groups. If the cereal box has a movie character appearing on it, then the product has more advertising to children. One reason may be that movie cobranding involves movies that target younger audiences. This effect disappears with teens, however. Breakfast cereals that cobrand a cartoon or TV character advertise less to teens and adults. This shows that firms consider the subject matter they promote to specific audiences. That is, teens and adults may not identify with cartoon characters, and therefore, advertising such products to these age groups would be ineffective.

Interestingly, there is a consistent negative effect of cobranding TV characters with advertising to all age groups. This may be that firms attempt to avoid redundant advertising - that is, advertising a TV character on the cereal box and the cereal on TV. Put another way, breakfast cereal firms may rely on the regular TV airtime provided by TV characters rather than needing the extra paid airtime of advertising. Cobranding sports characters on the cereal box has a positive effect on advertising to adults, which again suggests that firms consider the subject matter they promote to their audiences.

Across all groups, the price of television advertising has a negative coefficient as would be expected. In addition, older cereals are advertised less, suggesting that more established brands utilize less television promotion. Market competition via brand advertising has a positive significant effect on teen advertising but a negative effect on adult advertising. This 
Table 6. Zero-Inflated Negative Binomial Estimates of Advertising GRPs with Lagged Values

\begin{tabular}{lccc}
\hline \hline & \multicolumn{3}{c}{ Advertising GRPs } \\
\cline { 2 - 4 } Variables & Children GRPs & Teen GRPs & Adult GRPs \\
\hline Market competition & 0.015 & $0.281^{* * *}$ & $-0.147^{* * *}$ \\
Calories & $-0.605^{*}$ & -0.1 & -0.0579 \\
Total fat & $5.655^{* *}$ & 2.072 & 0.119 \\
Sodium & 0.0152 & -0.0173 & $-0.0801^{* * *}$ \\
Fiber & -1.793 & -1.726 & $-3.468^{* *}$ \\
Sugar & $5.361^{* * *}$ & $1.106^{*}$ & $-4.159^{* * * *}$ \\
Protein & -4.655 & -2.931 & 0.984 \\
Organic & 0.235 & $0.249^{* *}$ & 0.168 \\
Product age & $-0.00989^{* * *}$ & $-0.00815^{* * *}$ & $-0.00745^{* * *}$ \\
Firm price.L & $-0.0156^{* * *}$ & $-0.00795^{*}$ & 0.00189 \\
Nutrition claim.L & 0.0754 & 0.0149 & $-0.250^{* *}$ \\
Game on box.L & 0.106 & 0.0829 & $0.127^{*}$ \\
Toy in box.L & -0.192 & -0.0887 & -0.0405 \\
Purchase deal.L & 0.3 & 0.0144 & 0.0481 \\
Game online.L & $0.400^{*}$ & $0.229^{*}$ & 0.108 \\
Brand character.L & $0.522^{* * *}$ & $0.285^{* * *}$ & 0.21 \\
Movie character.L & $0.367^{* *}$ & 0.161 & -0.00112 \\
Cartoon character.L & -0.277 & $-0.366^{* *}$ & $-0.573^{* * *}$ \\
TV character.L & $-0.357^{*}$ & $-0.350^{* *}$ & $-0.404^{* *}$ \\
Sports character.L & -0.532 & -0.201 & $0.485^{* *}$ \\
Observations & 5,715 & 5,715 & 5,715 \\
\hline \hline
\end{tabular}

Notes: ${ }^{* * *} P<0.01,{ }^{* *} P<0.05,{ }^{*} P<0.1$. Standard errors clustered by brand. GRP, gross rating point.

indicates interesting differences in competitive marketing strategies between firms.

\section{Robustness}

As previously discussed, our model estimates could be biased because of omitted variables, reverse causality, or simultaneity. Although fixed and time effects will help mitigate for omitted variables, we further estimate equation (1) using lagged box marketing and cobranding variables to attempt to control for simultaneity or reverse causality. We use lags of 1 week and 1 month but report only the former as the results for the latter are not meaningfully different (Table 6). As can be seen by comparing with the previous results, the primary findings do not change. In particular, the effect of sugar on children is still significant as are the same cobranding variables. With teenagers, many of the parameter estimates are significant at a low $P$ value, with the exception of the price effect. The estimates for adult GRPs do not change significantly.

We also estimate equation (1) including quarter-specific dummy variables interacted with firm dummy variables to control for firm-specific intertemporal 
differences. The estimates (not reported) for children and teen GRPs do not change significantly; however, the model for adult GRPs does not converge.

\section{Conclusions}

Our analysis provides insight for understanding how firms choose to advertise breakfast cereals on television and how to model such behavior. With the former, we find that product attributes, package characteristics, and cobranding have a significant impact on advertising decisions. Further, this effect varies by which age group is being targeted with this advertising. With regard to modeling advertising behavior, we find that accounting for the decision to advertise (i.e., pulse advertising) plays an important role for advertising to children. These results can provide a framework for examining other food products in competitive markets. Although we attempt to control for endogeneity, there may still be time-invariant factors that could bias our parameter estimates. A more detailed data set or structural modeling framework could be used to address this in the future.

Going forward, there are important policy implications to consider. Over the past decade, major food companies in the United States have received extensive scrutiny for advertising unhealthful products, particularly to children. In response, there have been both industry- and government-led initiatives proposed to restrict or reduce advertising to children. Only the former have been successfully implemented. Specifically, the Better Business Bureau has established the Children's Food and Beverage Advertising Initiative (CFBAI) to provide a framework for food industry companies to voluntarily self-regulate their advertising to children (see http://www.bbb.org). The target objectives of the CFBAI focus on regulating when ads can be shown (during children's programming vs. prime time) and the type of programming during which the ads can be shown based on audience composition (young children vs. adolescents). Prior research has questioned, however, the effectiveness of the CFBAI at actually limiting how much advertising children see for unhealthful products (Berning, Huang, and Rabinowitz, 2014; Berning and McCullough, 2013; Huang and Yang, 2013). The results of this research provide more insight, to both industry and government, regarding ways to make advertising restrictions more impactful. In particular, future efforts may want to give greater attention to other forms of package advertising and cobranding that are related, and likely complementary, to television advertising. Further, targeted advertising to children appears to be very different than advertising to adults or even teens. Although this suggests greater emphasis on child-targeted advertising, it is important to acknowledge how adults, the purchase decision makers, are also targeted.

Importantly, future efforts may also want to focus on ways targeted advertising can be used to guide more healthful choices. In particular, certain aspects of 
advertising and cobranding may be more effective than others for promoting healthy foods.

\section{References}

Anand, B.N., and R. Shachar. "Targeted Advertising as a Signal.” QME 7,3(2009):237-66. Andreyeva, T., I.R. Kelly, and J.L. Harris. "Exposure to Food Advertising on Television: Associations with Children's Fast Food and Soft Drink Consumption and Obesity." Economics \& Human Biology 9,3(2011):221-33.

Aoki, J.R., and E.S. Moore. "Self-Regulation as a Tool for Promoting Healthier Children's Diets: Can CARU and the CFBAI Do More?" Advances in Communication Research to Reduce Childhood Obesity. J.D. Williams, K.E. Pasch, and C.A. Collins, eds. New York: Springer, 2013, pp. 119-51.

Beales, J.H., III, and R. Kulick. "Does Advertising on Television Cause Childhood Obesity? A Longitudinal Analysis." Journal of Public Policy \& Marketing 32,2(2013):185-94.

Berning, J.P., H.H. Chouinard, and J.J. McCluskey. "Identifying Consumer Preferences for Nutrition Information on Grocery Store Shelf Labels.” Food Policy 35,5(2010):429-36.

Berning, J.P., R. Huang, and A. Rabinowitz. "An Evaluation of Government and Industry Proposed Restrictions on Television Advertising of Breakfast Cereals to Children.” Journal of Consumer Policy 37,4(2014):507-25.

Berning, J., and M. McCullough. "Advertising Soft Drinks to Children: Are Voluntary Restrictions Effective?” Agribusiness 29,4(2013):469-85.

Chandra, A. "Targeted Advertising: The Role of Subscriber Characterisics in Media Markets." Journal of Industrial Economics 57,1(2009):58-84.

Chandra, A., and U. Kaiser. "Targeted Advertising in Magazine Markets and the Advent of the Internet." Management Science 60,7(2014):1829-43.

Desrochers, D.M., and D.J. Holt. "Children's Exposure to Television Advertising: Implications for Childhood Obesity.” Journal of Public Policy \& Marketing 26,2(2007):182-201.

Dhar, T., and K. Baylis. "Fast-Food Consumption and the Ban on Advertising Targeting Children: The Quebec Experience.” Journal of Marketing Research 48,5(2011):799813.

Federal Trade Commission. A Review of Food Marketing to Children and Adolescents: Follow-Up Report. Washington, DC: Federal Trade Commission, 2012. Internet site: https://www.ftc.gov/sites/default/files/documents/reports/review-food-marketingchildren-and-adolescents-follow-report/121221foodmarketingreport.pdf (Accessed March 7, 2017).

Feinberg, F.M. "Pulsing Policies for Aggregate Advertising Models." Marketing Science 11,3(1992):221-34.

Frazier, W.C., III, and J.L. Harris. "Trends in Television Food Advertising to Young People: 2015 Update.” Rudd Brief, Storrs: University of Connecticut Rudd Center for Food Policy \& Obesity, 2016.

Geylani, T., J.J. Inman, and F. Ter Hofstede. "Image Reinforcement or Impairment: The Effects of Co-branding on Attribute Uncertainty.” Marketing Science 27,4(2008):730-44.

Goettler, R.L. "Advertising Rates, Audience Composition, and Competition in the Network Television Industry.” Working paper, Chicago, IL: University of Chicago, 2012.

Goldfarb, A., and C. Tucker. "Online Display Advertising: Targeting and Obtrusiveness." Marketing Science 30,3(2011a):389-404. 
_. "Privacy Regulation and Online Advertising." Management Science 57,1(2011b):5771.

Huang, R., and M. Yang. "Buy What Is Advertised on Television? Evidence from Bans on Child-Directed Food Advertising." Journal of Public Policy \& Marketing 32,2(2013):207-22.

Iyer, G., D. Soberman, and J.M. Villas-Boas. “The Targeting of Advertising.” Marketing Science 24,3(2005):461-76.

Jargon, J. "Success Is Only So Sweet in Remaking Cereals.” Wall Street Journal, October 11, 2011, B1.

Johnson, J.P. “Targeted Advertising and Advertising Avoidance.” RAND Journal of Economics 44,1(2013):128-44.

Kelly, K.J., M.D. Slater, D. Karan, and L. Hunn. "The Use of Human Models and Cartoon Characters in Magazine Advertisements for Cigarettes, Beer, and Nonalcoholic Beverages." Journal of Public Policy \& Marketing 19,2 (2000):189-200.

Lee, M., Y. Choi, E.T. Quilliam, and R.T. Cole. "Playing with Food: Content Analysis of Food Advergames." Journal of Consumer Affairs 43,1(2009):129-54.

Mallinckrodt, V., and D. Mizerski. "The Effects of Playing an Advergame on Young Children's Perceptions, Preferences, and Requests.” Journal of Advertising 36,2(2007):87-100.

McGinnis, J.M., J.A. Gootman, and V.I. Kraak, eds. Food Marketing to Children and Youth: Threat or Opportunity? Washington, DC: National Academies Press, 2006.

Nelson, J.P. “Alcohol Advertising in Magazines: Do Beer, Wine, and Spirits Ads Target Youth?” Contemporary Economic Policy 24,3(2008):357-69.

Nelson, J.P., and D.J. Young. "Effects of Youth, Price, and Audience Size on Alcohol Advertising in Magazines." Health Economics 17,4(2008):551-56.

Nevo, A. "Measuring Market Power in the Ready-to-Eat Cereal Industry." Econometrica 69,2(2001):307-42.

Ogden, C.L., M.D. Carroll, and B.K. Kit. "Prevelance of Childhood and Adult Obesity in the United States, 2011-2012.” JAMA 311,8(2014):806-814.

Rao, A.R., L. Qu, and R.W. Ruekert. "Signaling Unobservable Product Quality through a Brand Ally." Journal of Marketing Research 36,2(1999):258-68.

Rao, A.R., and R.W. Ruekert. "Brand Alliances as Signals of Product Quality." Sloan Management Review 36,1(1994):87-97.

Schwartz, M.B., C. Ross, J.L. Harris, D.H. Jernigan, M. Siegel, J. Ostroff, and K.D. Brownell. "Breakfast Cereal Industry Pledges to Self-Regulate Advertising to Youth: Will They Improve the Marketing Landscape?” Journal of Public Health Policy 31,1(2010):59_ 73.

Simon, H. "ADPULS: An Advertising Model with Wearout and Pulsation." Journal of Marketing Research 19,3(1982):352-63.

Zywicki, T.J., D. Holt, and M. Ohlhausen. "Obesity and Advertising Policy.” George Mason University Law Review 12,4(2004):979-1011. 